\title{
New Macrocyclic Compound as Chiral Shift Reagent for Carboxylic Acids
}

\author{
Fengnian Ma, Lin Ai, Xiumin Shen. Cong Zhang* \\ College of Chemistry, Beijing Normal University, Beijing, 100875, China \\ czhang@bnu.edu.cn
}

Supporting Information

\section{Synthesis of Aminonaphthol 1}

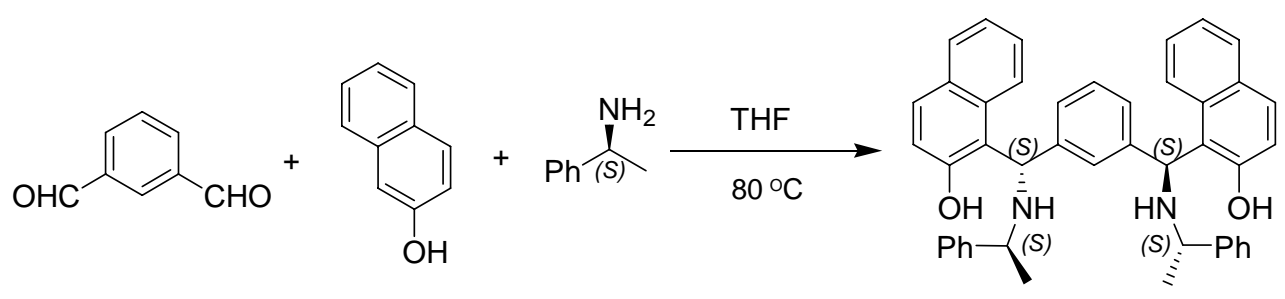

1

Aminonaphthol 1 was synthesized according published methods. ${ }^{1}$

A mixture of $m$-benenedialdehyde $(2.68 \mathrm{~g}, 20 \mathrm{mmol}), 2$-naphthol $(6.05 \mathrm{~g}, 42 \mathrm{mmol})$ and (S)-(-)-1-phenylethanamine in $10 \mathrm{~mL}$ THF was stirred at $80{ }^{\circ} \mathrm{C}$ under a nitrogen atmosphere for $3 \mathrm{~d}$. Then the reaction mixture was purified by flash chromatography (acetone: petrol ether $=1: 10$ ) affording crude $\mathbf{1}$ as yellow solid, recrystallized with THF and hexane affording colorless crystal (4.83 g, $38.5 \%$ yield).

${ }^{1} \mathrm{H}$ NMR (500 MHz, $\left.\mathrm{CDCl}_{3}, \mathrm{ppm}\right): \delta: 1.49$ (d, $\left.J=6.5 \mathrm{~Hz}, 6 \mathrm{H}\right), 2.25$ (br s, 2H), 3.84 (q, $J=5.9 \mathrm{~Hz}$, 2H), 5.31 (s, 2H), 6.88-7.77 (stack, 26H, Aromatic Protons), 13.51 (bs s, 2H) 


\section{Synthesis of Macrocyclic Compound 3}

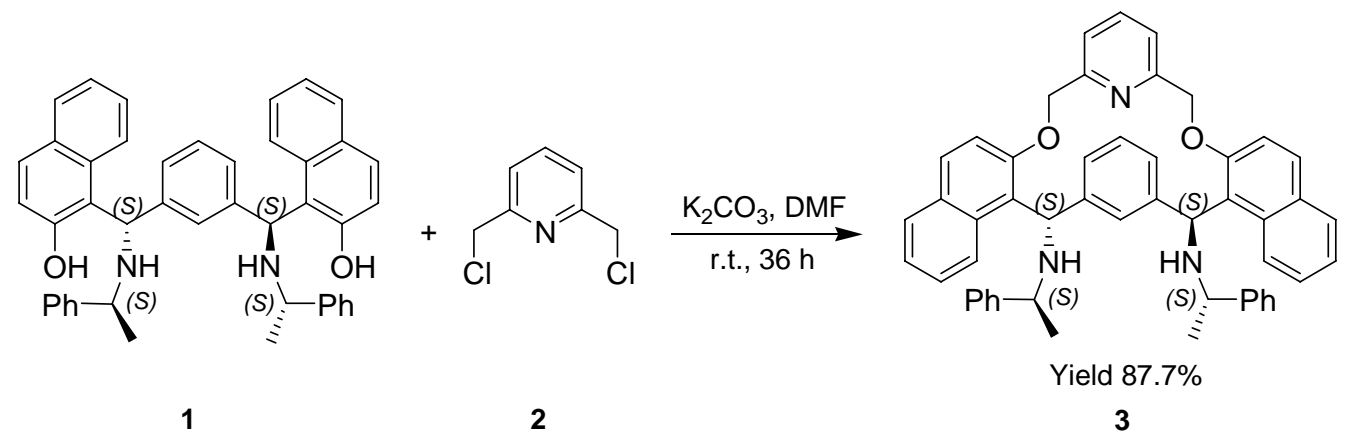

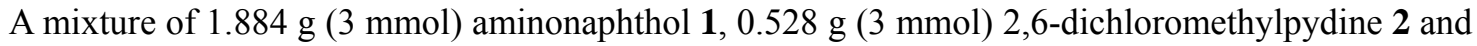
$4.14 \mathrm{~g}(30 \mathrm{mmol}) \mathrm{K}_{2} \mathrm{CO}_{3}$ in $60 \mathrm{~mL}$ dry DMF was stirred at room temperature for $36 \mathrm{~h}$. Then it was poured into $150 \mathrm{~mL}$ water and extracted with toluene $(20 \mathrm{~mL} \times 3)$, washed with water $(20 \mathrm{~mL})$ and brine $(20 \mathrm{~mL})$. The organic phase was dried with $\mathrm{Na}_{2} \mathrm{SO}_{4}$, filtrated and concentrated. The residue was purified by flash chromatography (acetone: petrol ether $=1: 6)$ affording 3 as white solid (1.923 $\mathrm{g}$, $87.7 \%$ yield), recrystallized with THF and hexane affording colorless crystal.

mp 237-238 ${ }^{\circ} \mathrm{C} .[\alpha]_{\mathrm{D}}^{20}+17.1^{\circ}(c=0.6, \mathrm{THF}) .{ }^{1} \mathrm{H}$ NMR $\left(500 \mathrm{MHz}, \mathrm{CDCl}_{3}, \mathrm{ppm}\right): \delta: 1.17(\mathrm{~d}, J=6.3$ $\mathrm{Hz}, 6 \mathrm{H}), 3.59$ (q, J = 6.3 Hz, 2H), 4.22 (br s, 2H), $5.26(\mathrm{~s}, 2 \mathrm{H}), 5.30(\mathrm{~s}, 2 \mathrm{H}), 5.44(\mathrm{~s}, 2 \mathrm{H}), 6.82-8.43$ (stack, 29H, Aromatic Protons); ${ }^{13} \mathrm{C}$ NMR (125 MHz, $\left.\mathrm{CDCl}_{3}, \mathrm{ppm}\right): \delta: 25.29,55.71,57.12,71.54$, $114.53,121.66,123.07,123.50,124.86,125.80,126.56,127.19,127.32,128.09,128.57,129.02$, 129.56, 134.04, 137.27, 143.33, 146.47, 154.94, 155.82; IR (KBr): $3453 \mathrm{~cm}^{-1}$; MS (EI): 731 (M ); EA for $\mathrm{C}_{51} \mathrm{H}_{45} \mathrm{~N}_{3} \mathrm{O}_{2}$ : calcd C 83.69, H 6.20, N 5.74; found C 83.53, H 6.53, N 5.59. Crystallographic data have been deposited at the Cambridge Crystallographic Data Center (CCDC) under accession number 614539. 


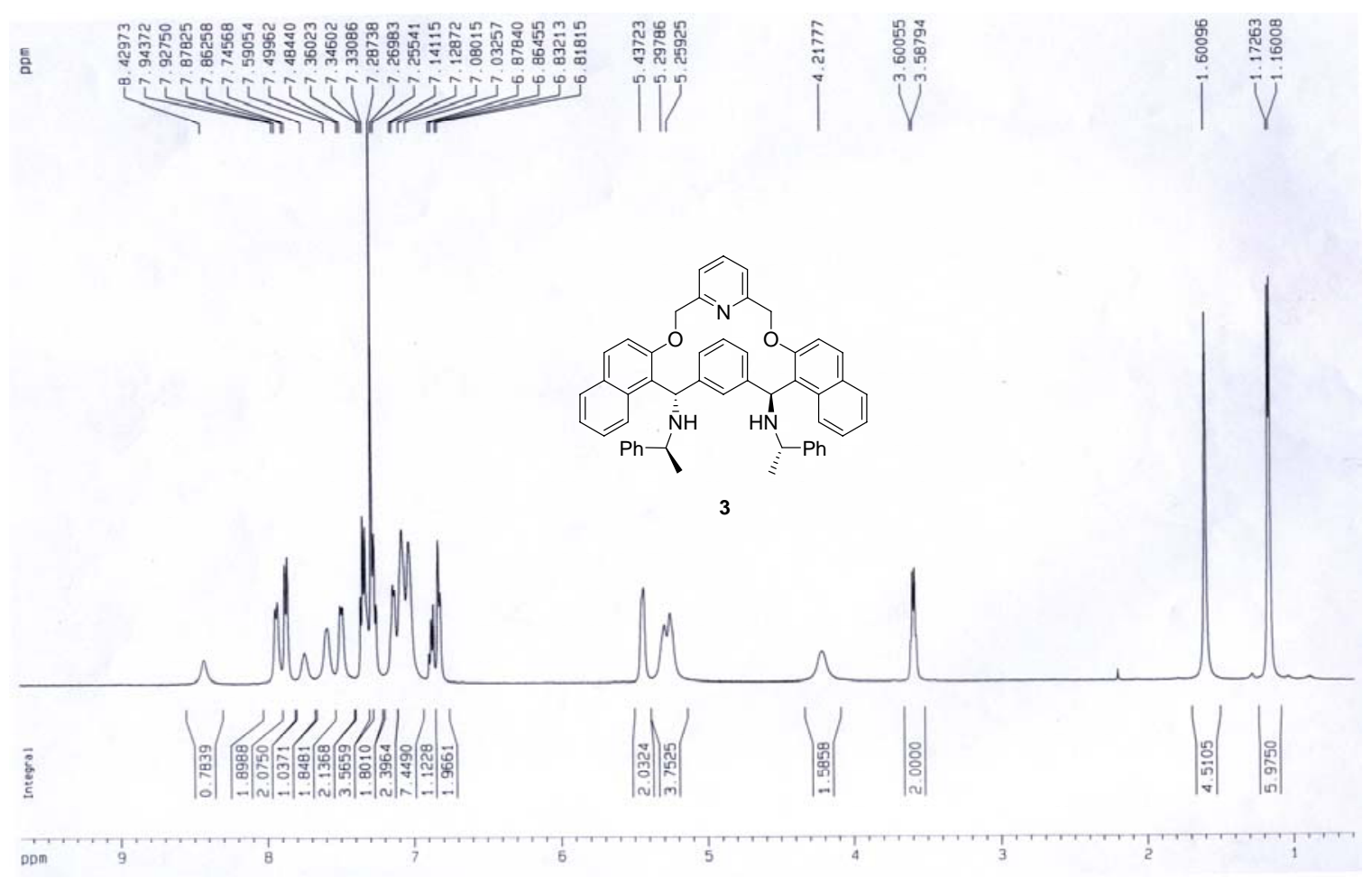

Figure S1. ${ }^{1} \mathrm{H}$ NMR spectrum $\left(\mathrm{CDCl}_{3}, 500 \mathrm{MHz}\right)$ of the new macrocyclic compound 3
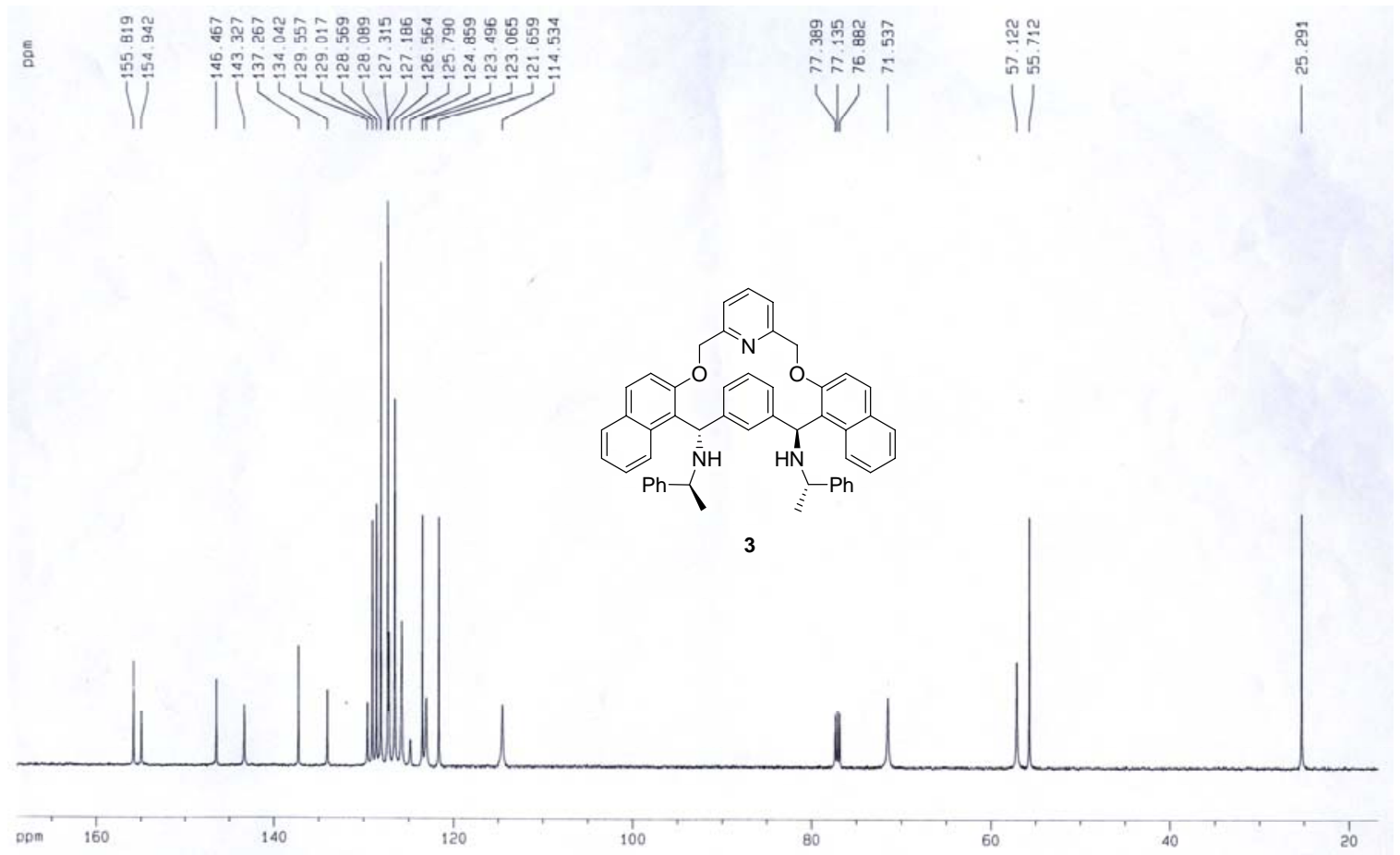

Figure S2. ${ }^{13} \mathrm{C}$ NMR spectrum $\left(\mathrm{CDCl}_{3}, 125 \mathrm{MHz}\right)$ of the new macrocyclic compound 3 
<smiles></smiles>

3

(a)

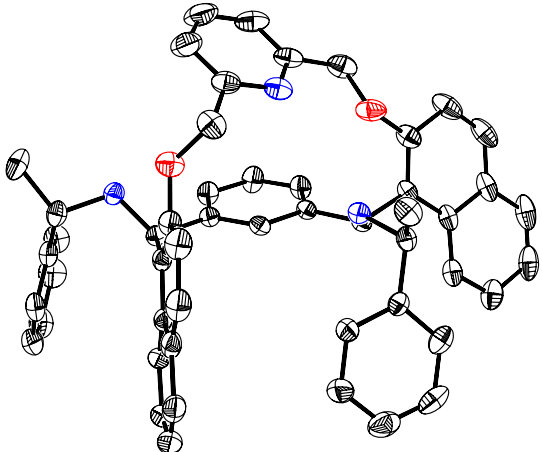

(b)

Figure S3. (a)The structure of the new macrocyclic compound 3. (b)X-Ray structure of the new macrocyclic compound 3

\section{Determination of stoichiometry by ${ }^{1} \mathrm{H}$ NMR titrations.}

The host 3, $(R)$ - and (S)-mandelic acid were separately dissolved in $\mathrm{CDCl}_{3}$ with a concentration of 5 $\mathrm{mM}$. These solutions were distributed among 11 NMR tubs, with various amounts of host $\mathbf{3}$ and guest $((R)$ - or $(S)$-mandelic acid), so that the total concentration of host and guest was $5 \mathrm{mM}$, the mole ratio of the host to the gust of the 11 tubes was $0,0.10,0.20,0.25,0.33,0.4,0.5,0.67,1,2,4$. The ${ }^{1} \mathrm{H}$ NMR spectrum of each sample was recorded on a $500 \mathrm{MHz}$ spectrometer. The data were fit to a 1:2 (host to guest) binding profile according to the Job plots ${ }^{2}$, using the chemical shift changes $(\Delta \delta)$ of the $\alpha$-proton of mandelic acid. All recorded Job plots were found to exhibit maxima at 0.67 . This indicates that 3 forms a 1:2 complex with the mandelic acids.

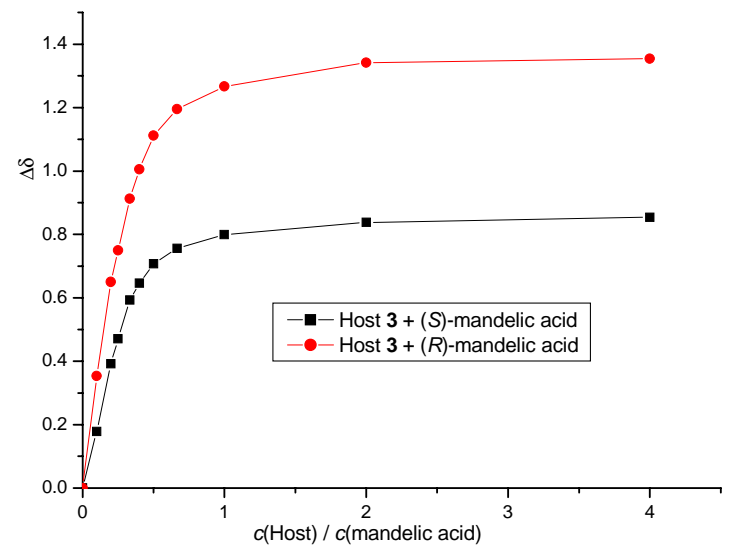

Figure S4. Experimental data obtained for the ${ }^{1} \mathrm{H}$ NMR titrations. The $\Delta \delta$ standing for chemical shift change of the $\alpha$-proton of guest $((R)$ - or $(S)$-mandelic acid) in presence of host 3. 


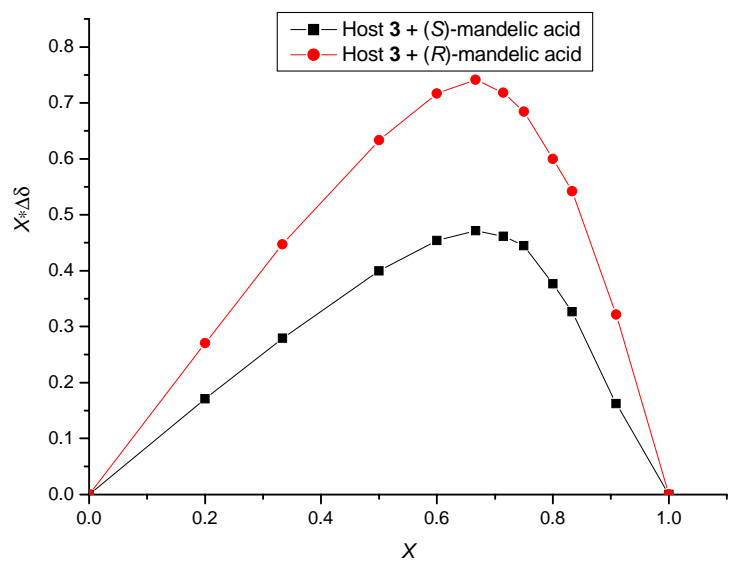

Figure S5. Job plots for the complexation of host 3 with guest ((R)- or $(S)$-mandelic acid). The $\Delta \delta$ standing for chemical shift change of the $\alpha$-proton of guest $((R)$ - or $(S)$-mandelic acid) in presence of host 3, $X$ standing for the mole fraction of host 3, $(X=[3] /([3]+[$ guest $]))$.

\section{Study of the discrimination ability of host 3 towards various racemic guests 4-16.}

All samples were prepared by adding 0.5 equivalent of host 3 to a $\mathrm{CDCl}_{3}$ solution of the guests ( 4 $\mathrm{mM})$. The ${ }^{1} \mathrm{H}$ NMR spectra were registered at room temperature using a $500 \mathrm{MHz}$ instrument.

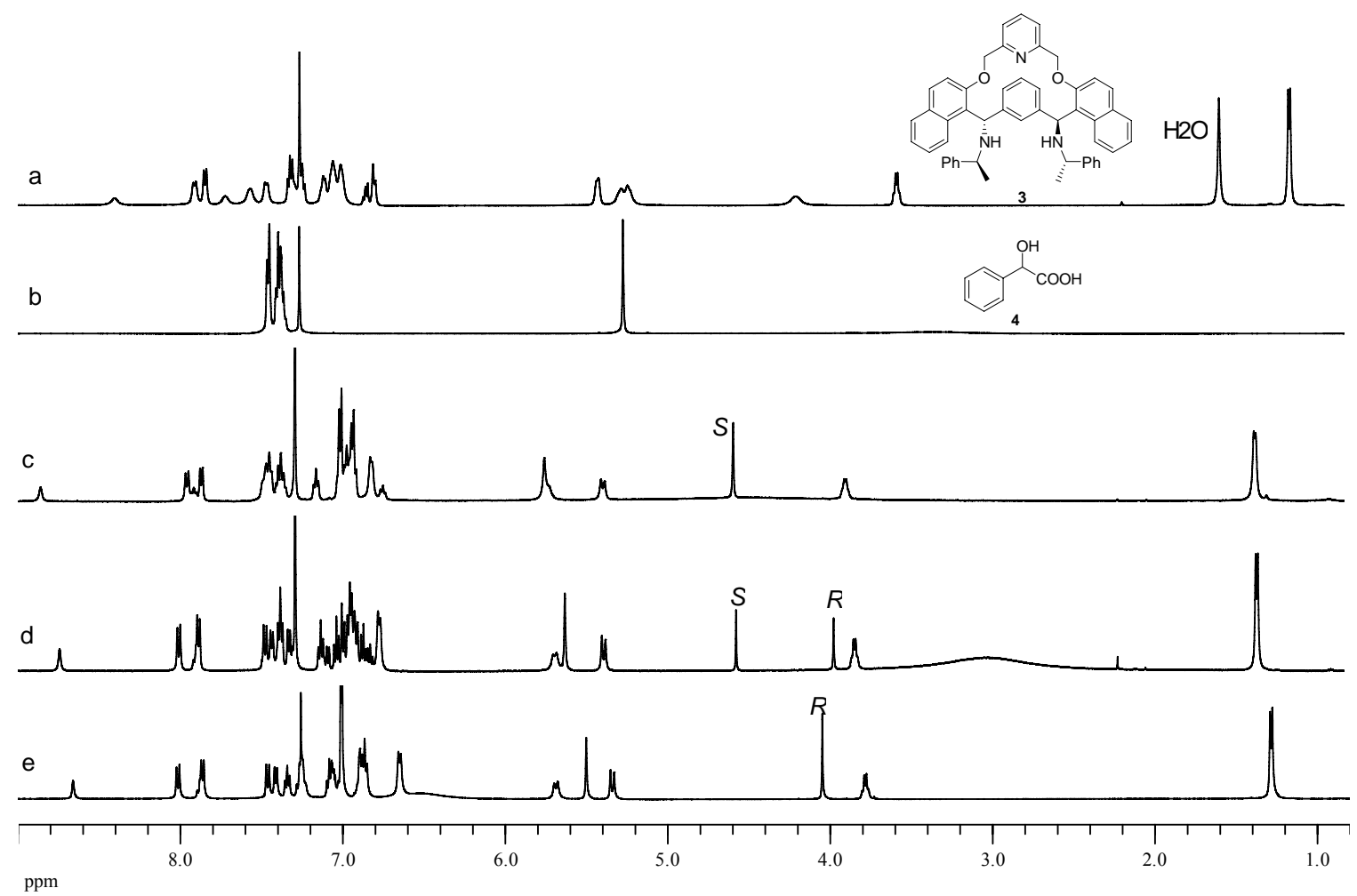

Figure S6. The overlaid ${ }^{1} \mathrm{H}$ NMR spectra $\left(\mathrm{CDCl}_{3}, 500 \mathrm{MHz}\right)$ of host $3(\mathrm{a})$, guest 4 (b), the 1:2 mixture of 3 with (S)-4 (c), (RS)-4 (d), (R)-4 (e). 


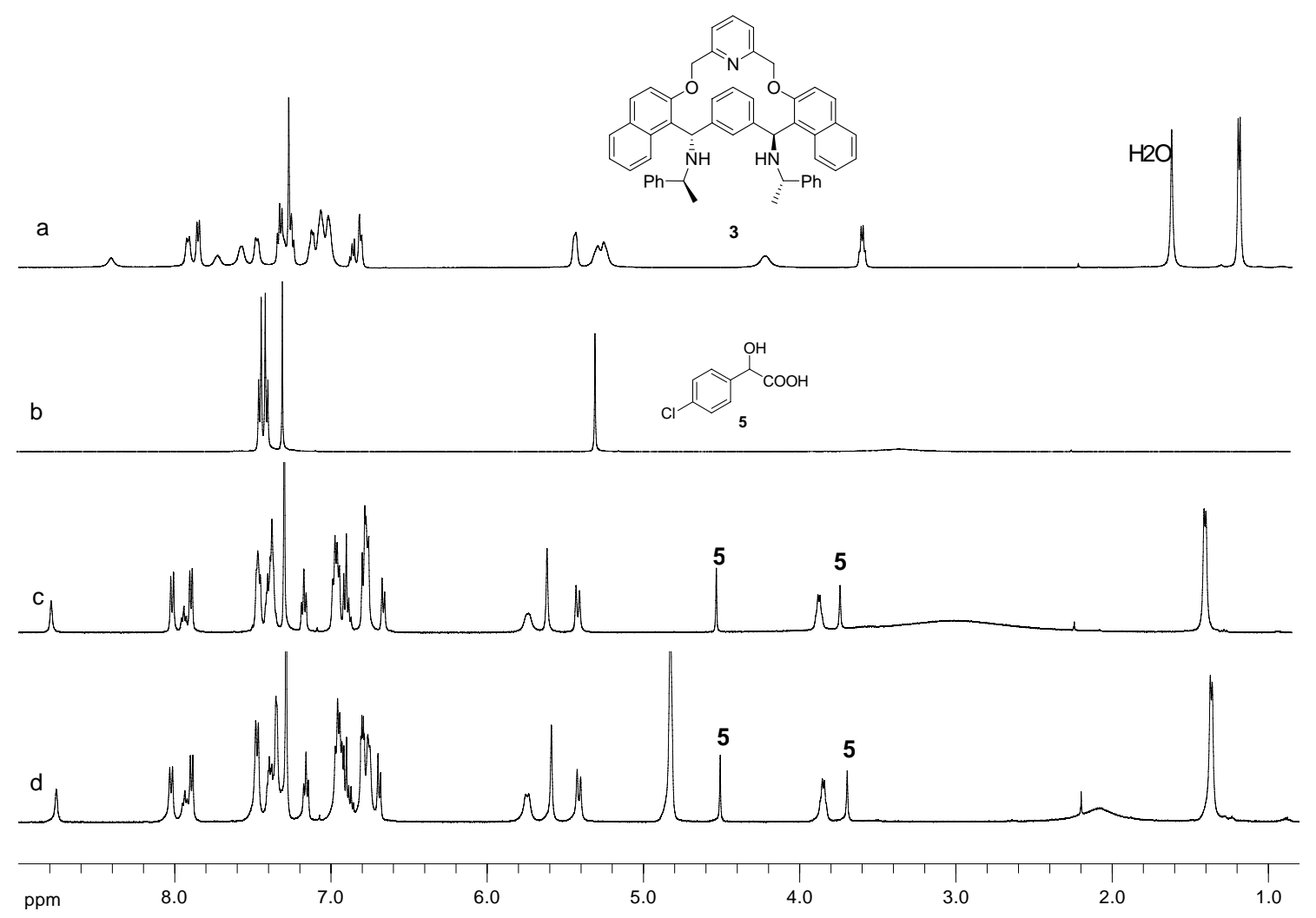

Figure S7. The overlaid ${ }^{1} \mathrm{H}$ NMR spectra $\left(\mathrm{CDCl}_{3}, 500 \mathrm{MHz}\right)$ of host 3 (a), guest 5 (b), the $1: 2$ mixture of 3 with (RS)-5 (c), the 1:2 mixture of 3 with (RS)-5, $\mathrm{D}_{2} \mathrm{O}$ exchanged (d)

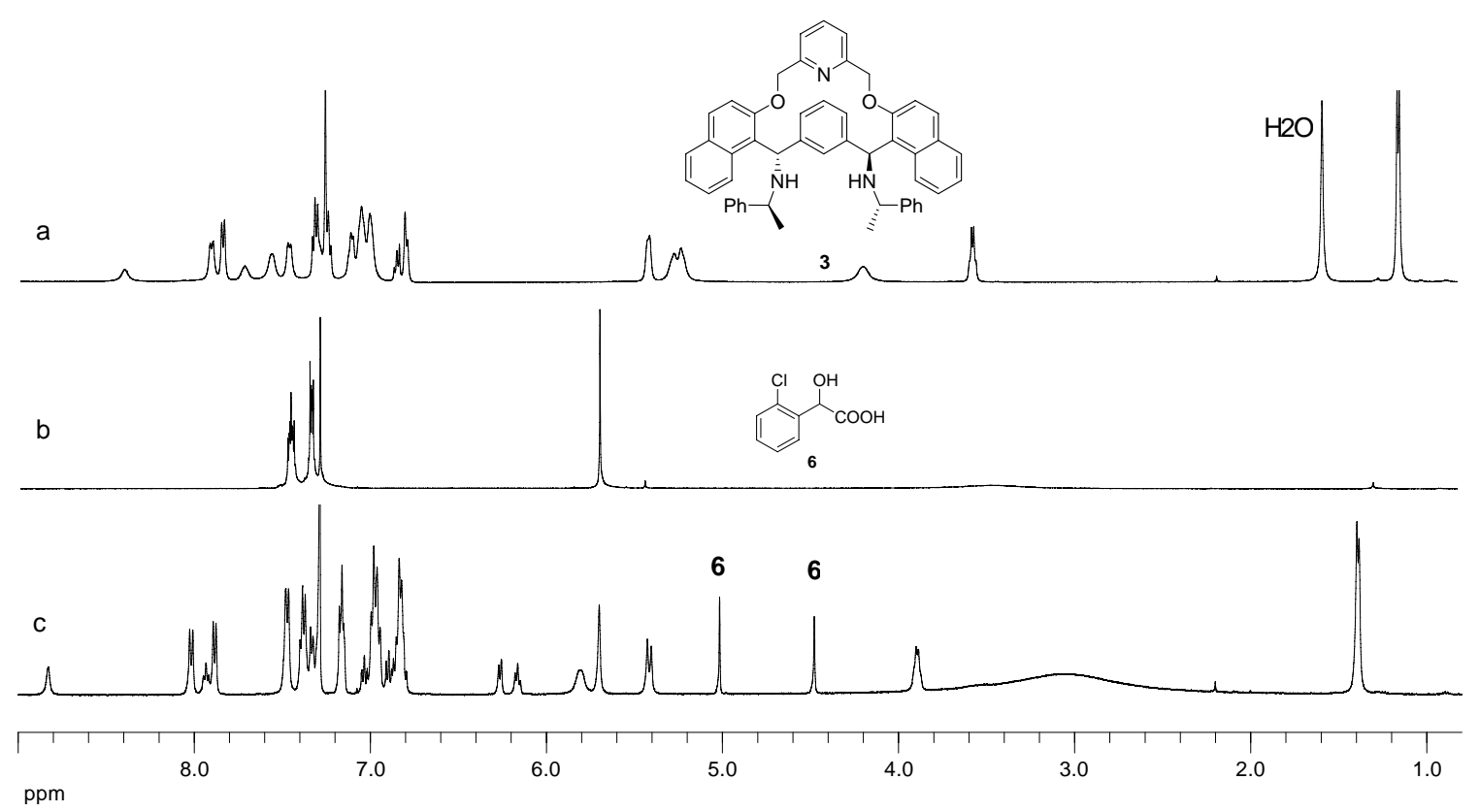

Figure S8. The overlaid ${ }^{1} \mathrm{H}$ NMR spectra $\left(\mathrm{CDCl}_{3}, 500 \mathrm{MHz}\right)$ of host 3 (a), guest 6 (b), the 1:2 mixture of $\mathbf{3}$ with (RS)-6 (c) 


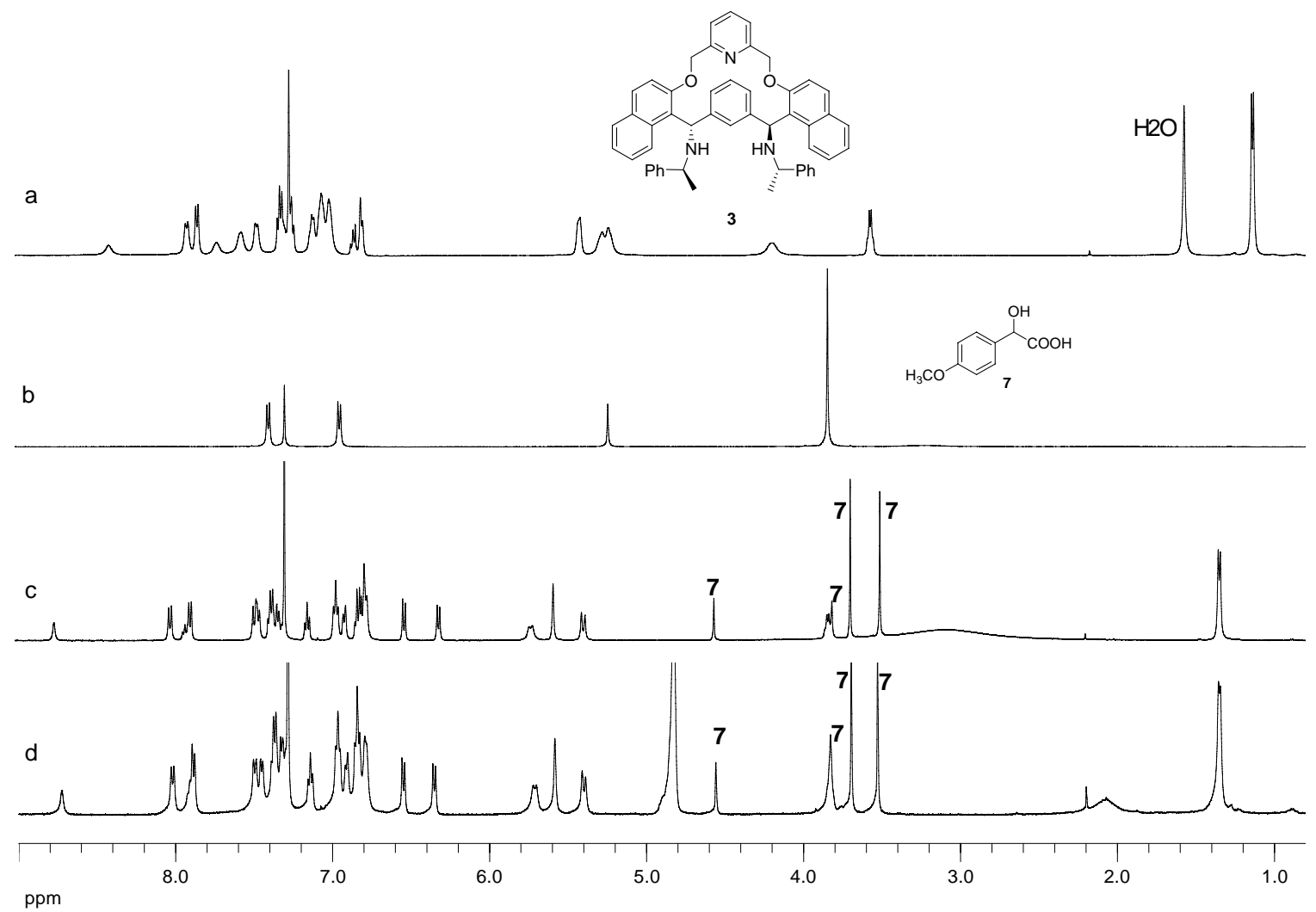

Figure S9. The overlaid ${ }^{1} \mathrm{H}$ NMR spectra $\left(\mathrm{CDCl}_{3}, 500 \mathrm{MHz}\right)$ of host 3 (a), guest $\mathbf{7}$ (b), the 1:2 mixture of 3 with (RS)-7 (c), the 1:2 mixture of 3 with (RS)-7, $\mathrm{D}_{2} \mathrm{O}$ exchanged (d)

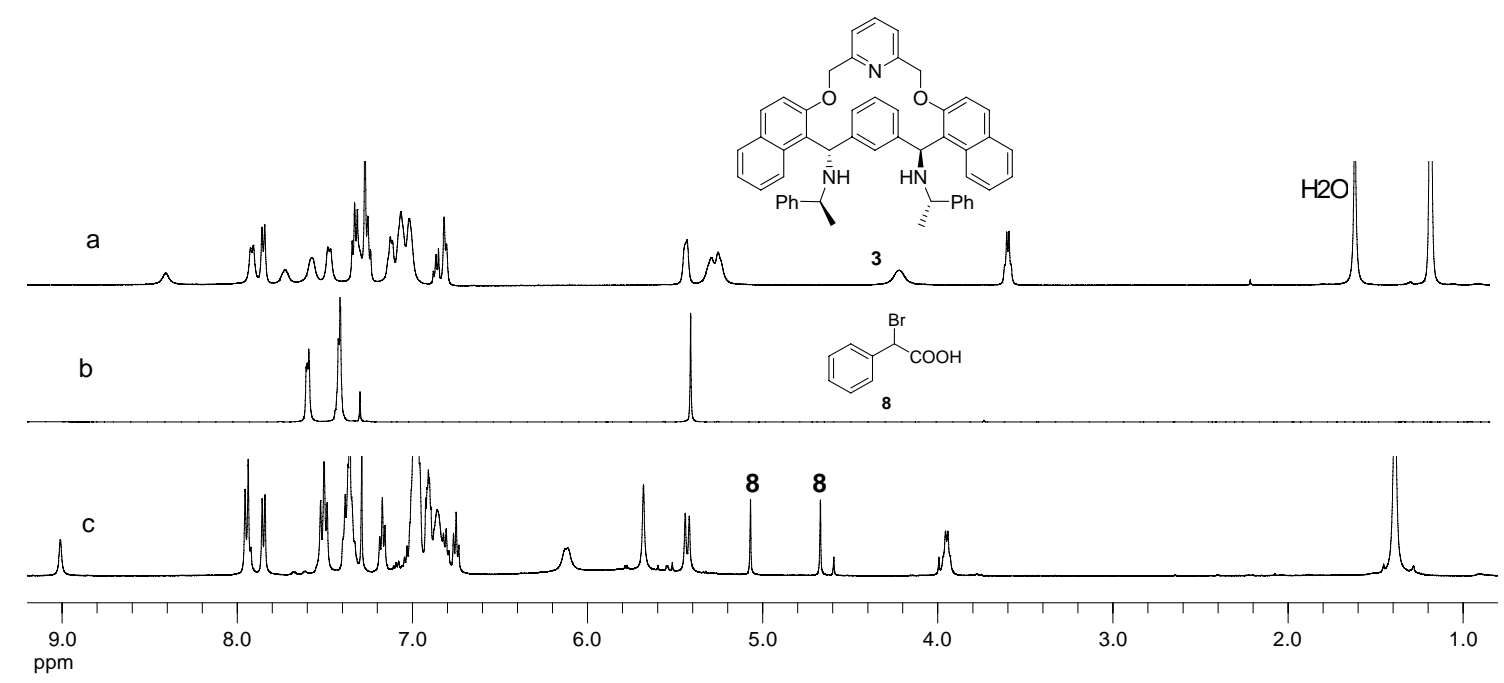

Figure S10. The overlaid ${ }^{1} \mathrm{H}$ NMR spectra $\left(\mathrm{CDCl}_{3}, 500 \mathrm{MHz}\right)$ of host 3 (a), guest 8 (b), the 1:2 mixture of $\mathbf{3}$ with $(R S)-\mathbf{8}(\mathrm{c})$ 


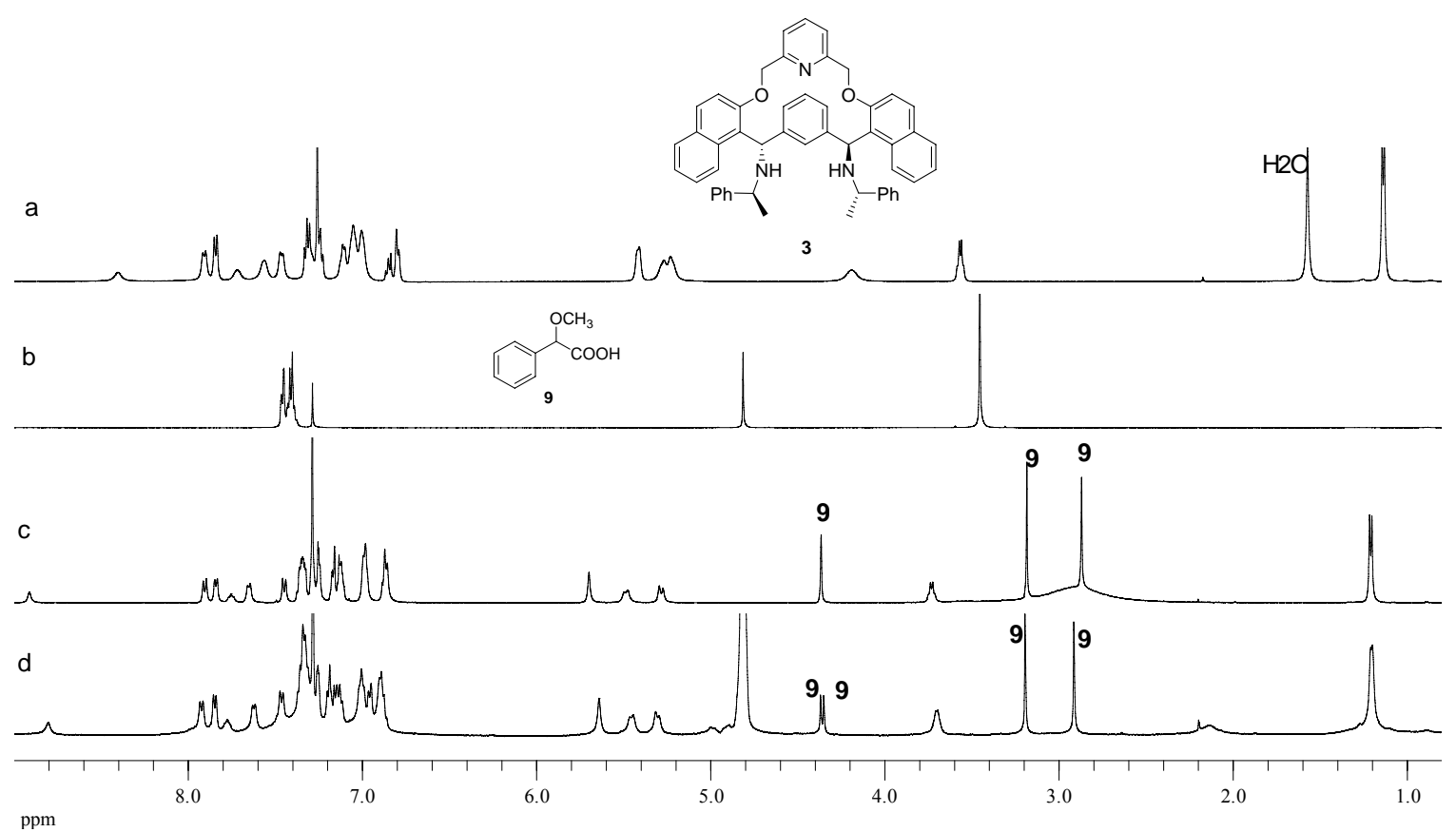

Figure S11. The overlaid ${ }^{1} \mathrm{H}$ NMR spectra $\left(\mathrm{CDCl}_{3}, 500 \mathrm{MHz}\right)$ of host 3 (a), guest 9 (b), the 1:2 mixture of $\mathbf{3}$ with $(R S)-\mathbf{9}(\mathrm{c})$, the 1:2 mixture of $\mathbf{3}$ with $(R S)-\mathbf{9}, \mathrm{D}_{2} \mathrm{O}$ exchanged (d)

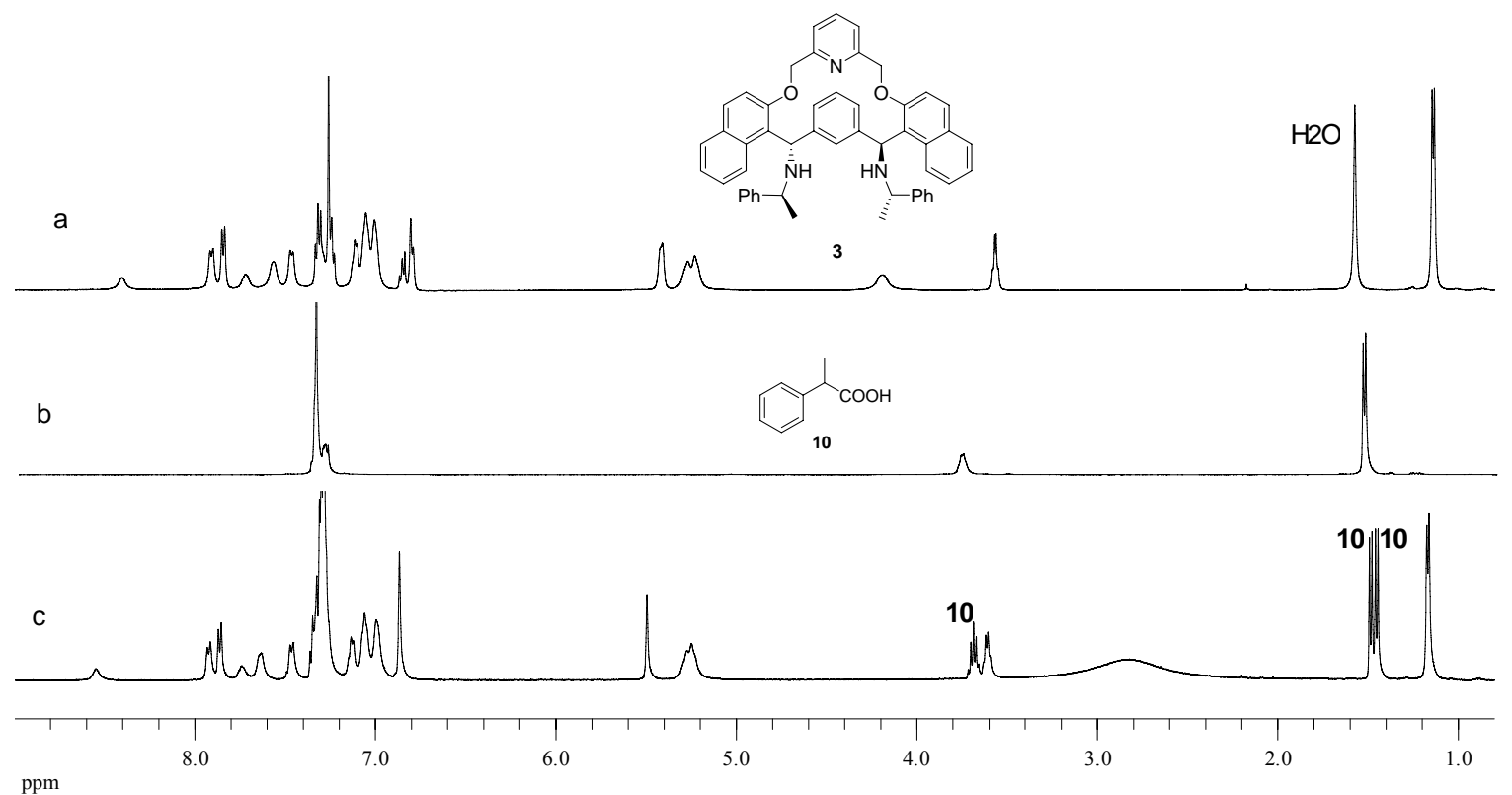

Figure S12. The overlaid ${ }^{1} \mathrm{H}$ NMR spectra $\left(\mathrm{CDCl}_{3}, 500 \mathrm{MHz}\right)$ of host $\mathbf{3}$ (a), guest $\mathbf{1 0}(\mathrm{b})$, the $1: 2$ mixture of $\mathbf{3}$ with (RS)-10 (c) 


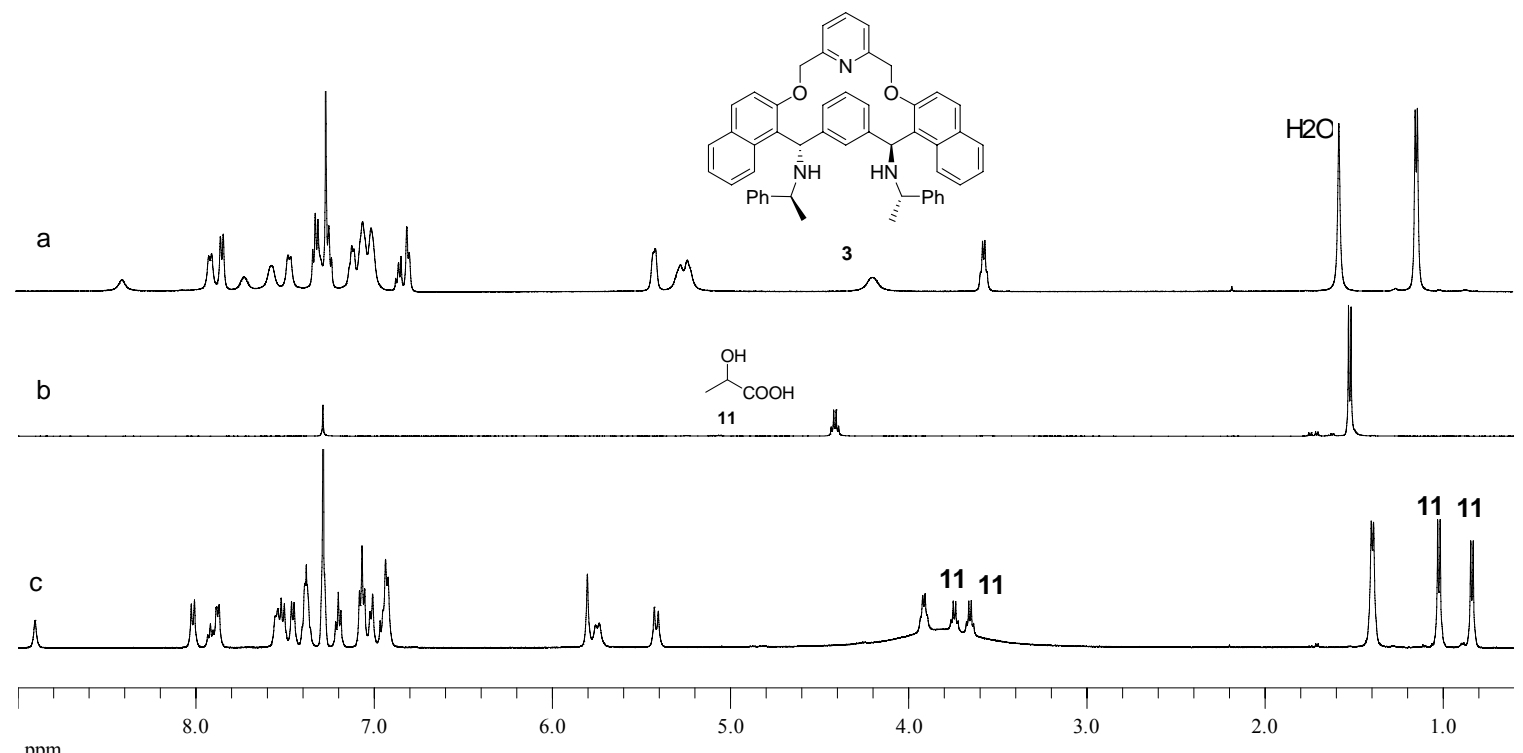

Figure S13. The overlaid ${ }^{1} \mathrm{H}$ NMR spectra $\left(\mathrm{CDCl}_{3}, 500 \mathrm{MHz}\right)$ of host 3 (a), guest 11 (b), the $1: 2$ mixture of $\mathbf{3}$ with (RS)-11 (c)

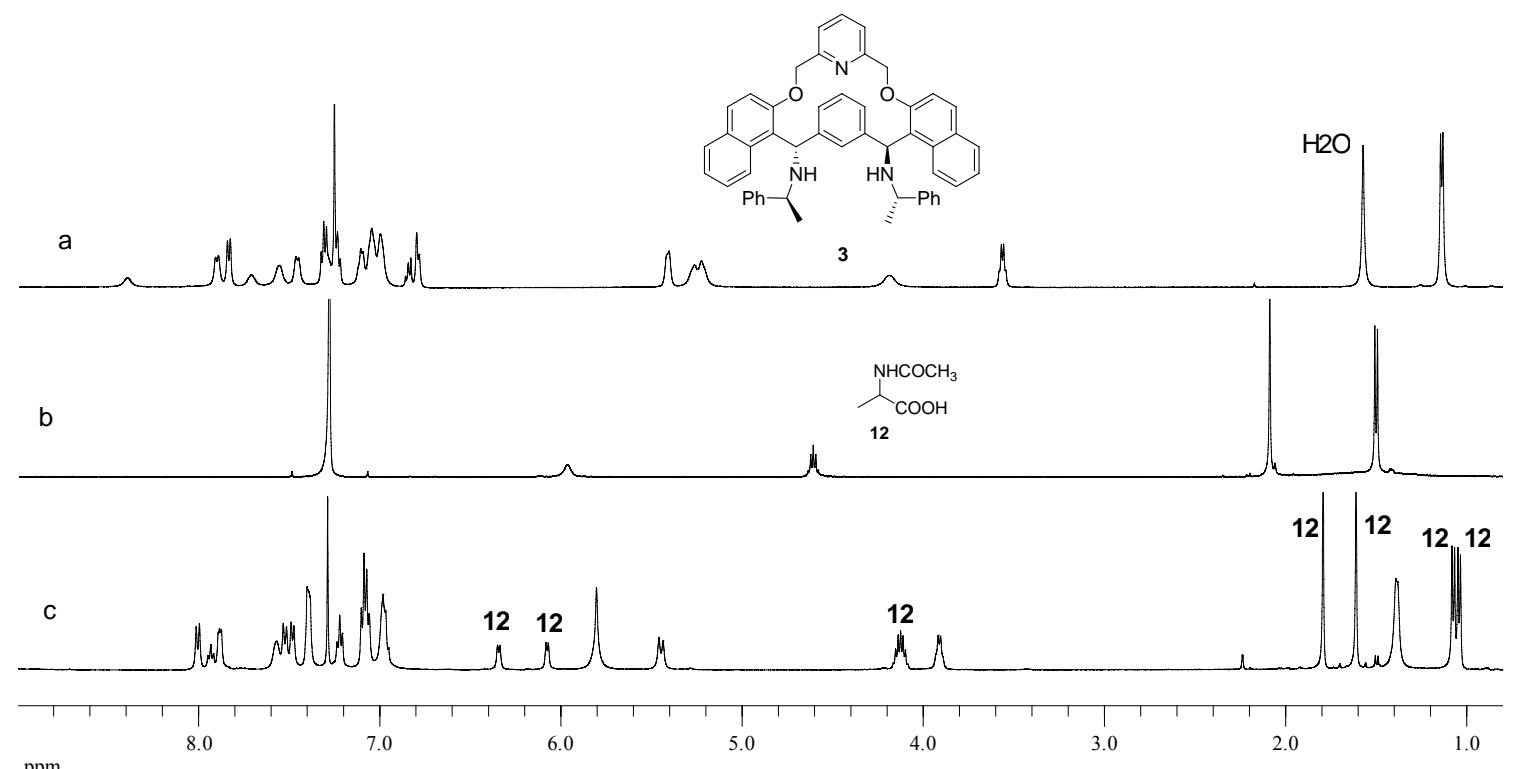

Figure S14. The overlaid ${ }^{1} \mathrm{H}$ NMR spectra $\left(\mathrm{CDCl}_{3}, 500 \mathrm{MHz}\right)$ of host 3 (a), guest 12 (b), the 1:2 mixture of 3 with (RS)-12 (c) 


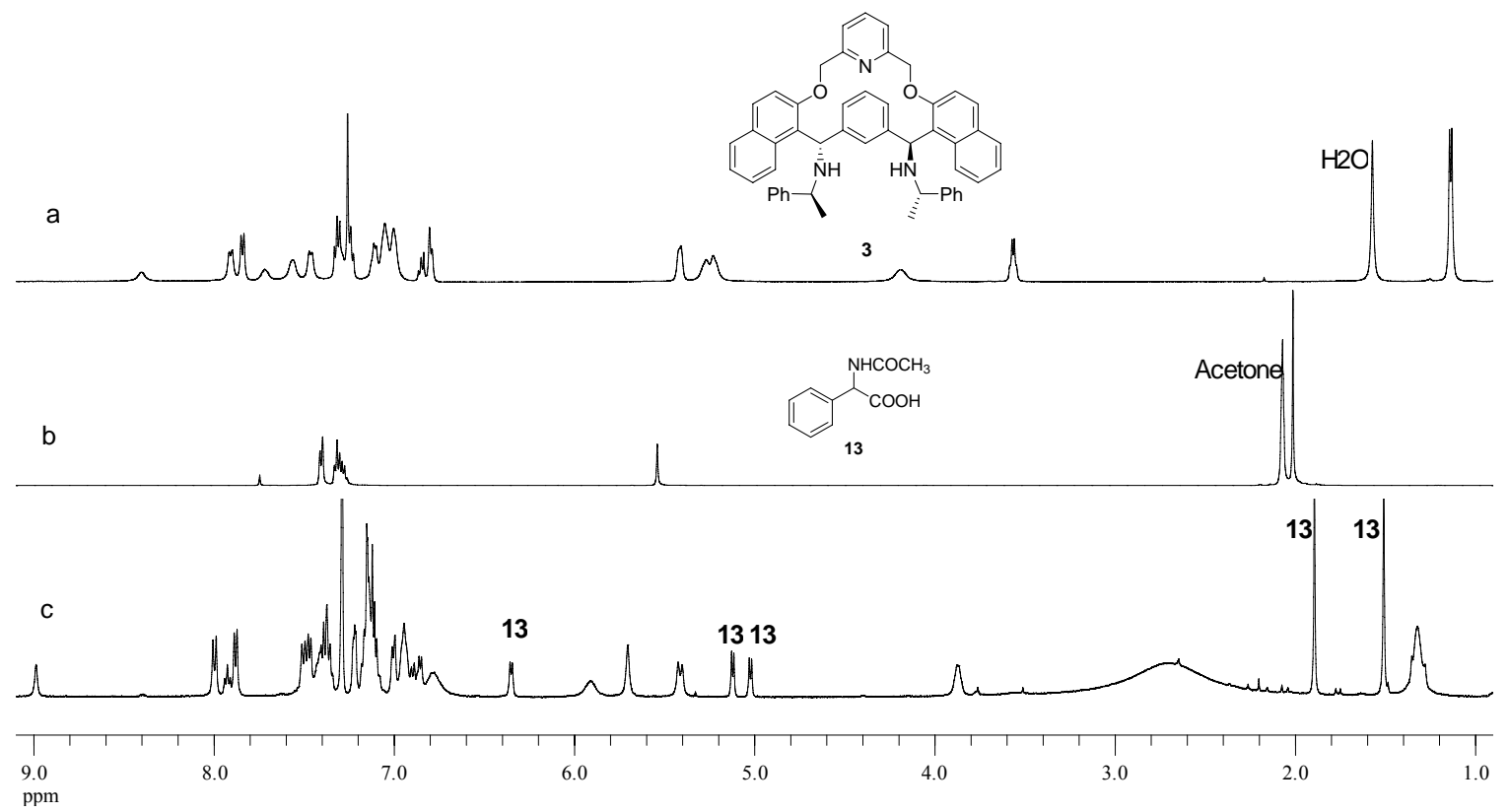

Figure S15. The overlaid ${ }^{1} \mathrm{H}$ NMR spectra $(500 \mathrm{MHz})$ of host 3 in $\mathrm{CDCl}_{3}$ (a), guest 13 in $\mathrm{CDCl}_{3} /$ Acetone- $d_{6}(\mathrm{~b})$, the 1:2 mixture of $\mathbf{3}$ with (RS)-13 in $\mathrm{CDCl}_{3}$ (c)

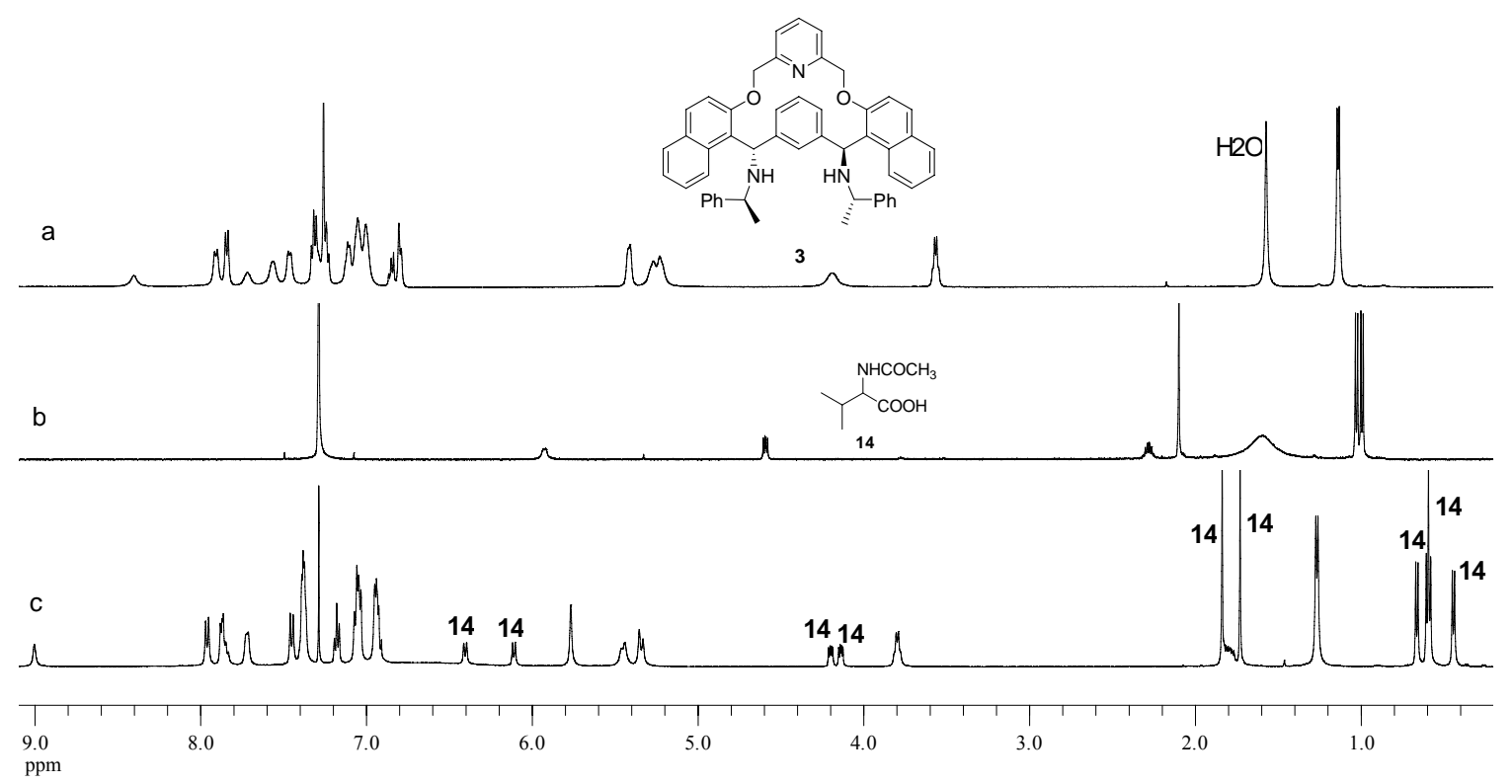

Figure S16. The overlaid ${ }^{1} \mathrm{H}$ NMR spectra $\left(\mathrm{CDCl}_{3}, 500 \mathrm{MHz}\right)$ of host 3 (a), guest 14 (b), the 1:2 mixture of 3 with (RS)-14 (c) 


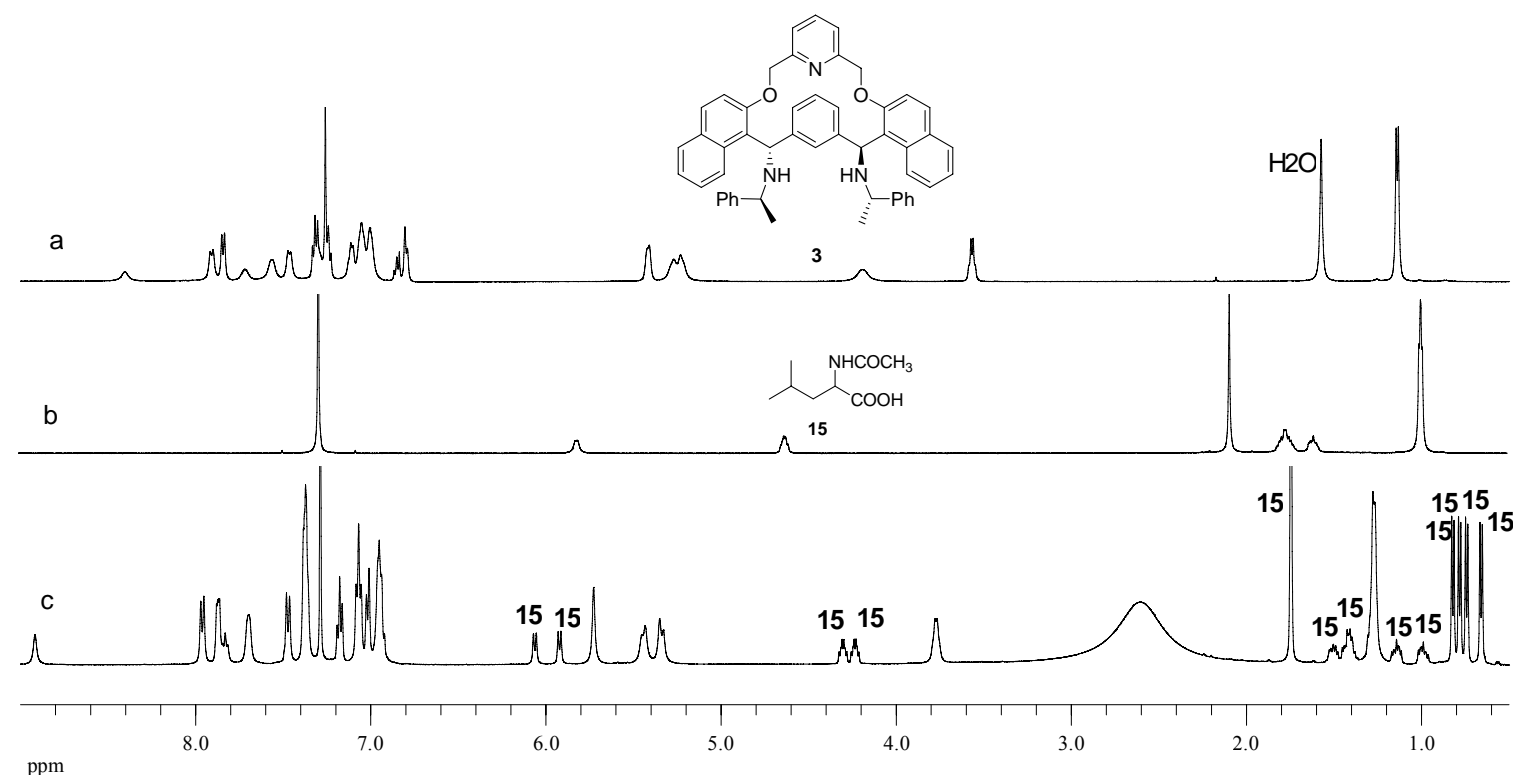

Figure S17. The overlaid ${ }^{1} \mathrm{H}$ NMR spectra $\left(\mathrm{CDCl}_{3}, 500 \mathrm{MHz}\right)$ of host $\mathbf{3}$ (a), guest $\mathbf{1 5}$ (b), the 1:2 mixture of $\mathbf{3}$ with (RS)-15 (c)

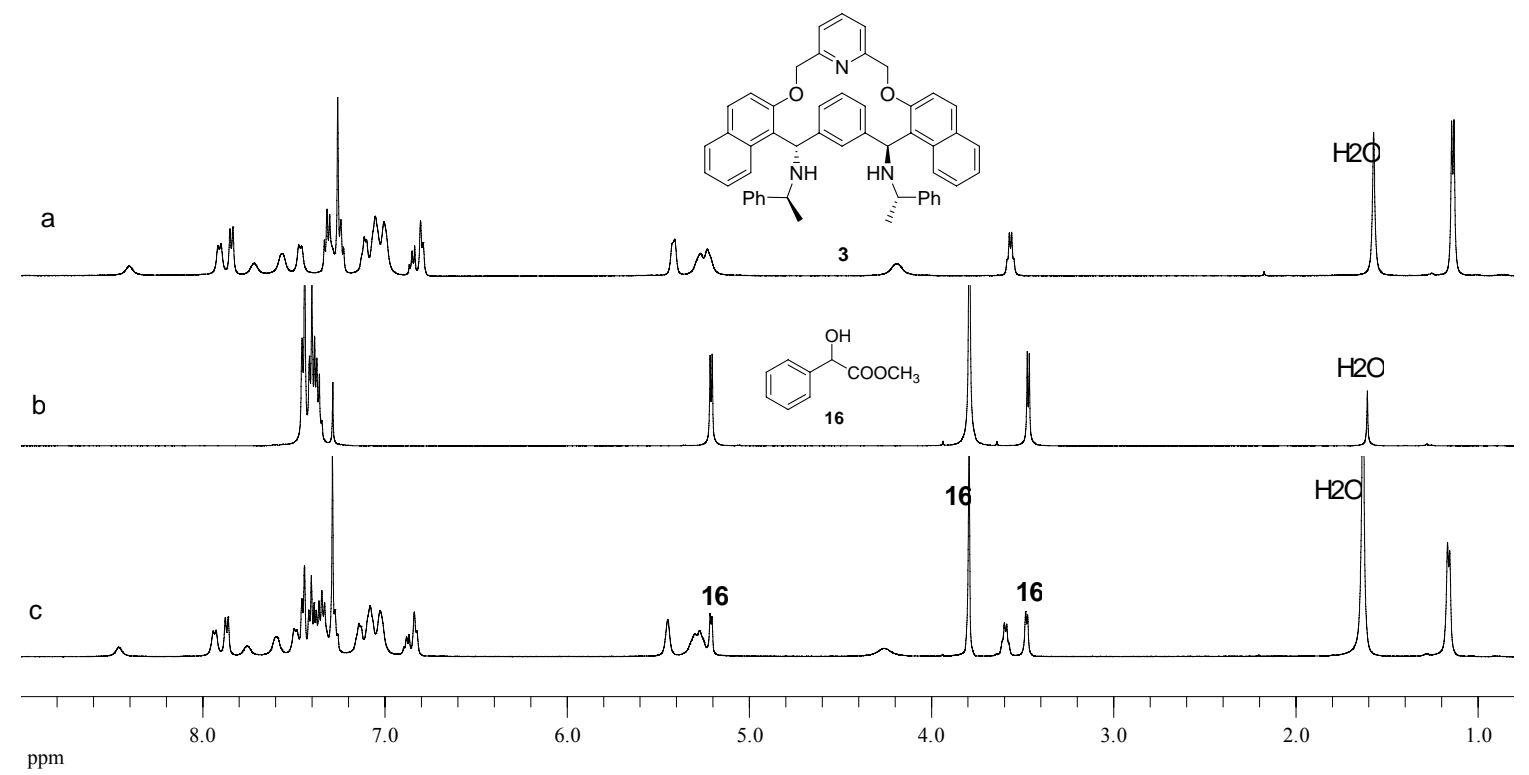

Figure S18. The overlaid ${ }^{1} \mathrm{H}$ NMR spectra $\left(\mathrm{CDCl}_{3}, 500 \mathrm{MHz}\right)$ of host $\mathbf{3}$ (a), guest 16 (b), the 1:2 mixture of 3 with (RS)-16 (c) 


\section{Study of the solvent effects of the discrimination ability of host 3.}

A mixture of host $\mathbf{3}$ and racemic guest $\mathbf{4}$ or $\mathbf{1 3}$ was dissolved in $\mathrm{CDCl}_{3}$ with the concentrations of 2 $\mathrm{mM}$ for host and $4 \mathrm{mM}$ for guest. $0.5 \mathrm{~mL}$ of these solutions was added to 5 NMR tubes, which contained $0.05 \mathrm{~mL}$ of $\mathrm{CDCl}_{3}$, benzene- $d_{6}$, acetone- $d_{6}, \mathrm{CD}_{3} \mathrm{OD}$ or DMSO- $d_{6}$. The ${ }^{1} \mathrm{H}$ NMR spectra were registered at room temperature using a $500 \mathrm{MHz}$ instrument.

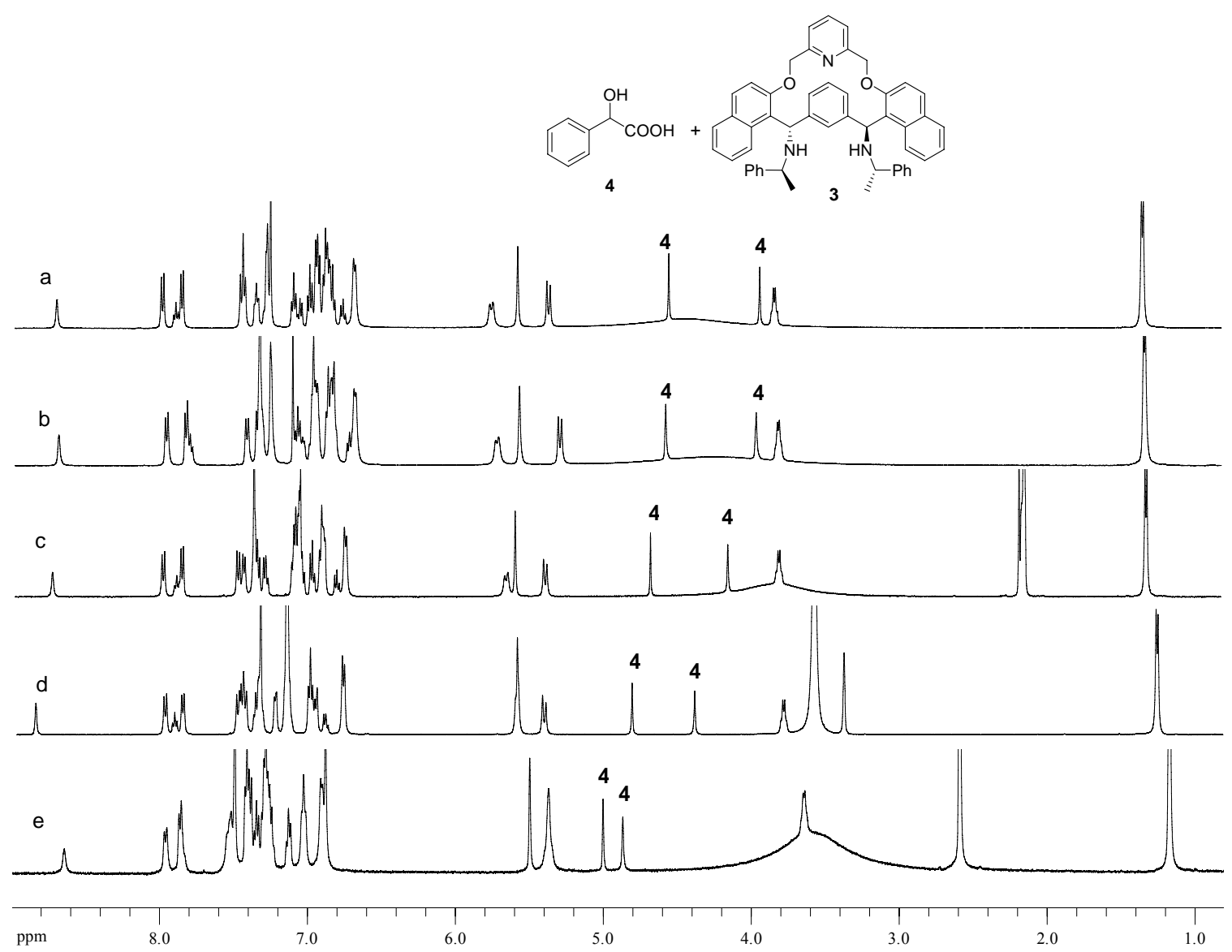

Figure S19. The overlaid ${ }^{1} \mathrm{H}$ NMR spectra $(500 \mathrm{MHz})$ of the $1: 2$ mixture of host 3 and guest 4 in various deuterated solvents. (a) $\mathrm{CDCl}_{3}$, (b) $\mathrm{CDCl}_{3} /$ benzene- $d_{6}$, (c) $\mathrm{CDCl}_{3} /$ acetone- $d_{6}$, (d) $\mathrm{CDCl}_{3} /$ $\mathrm{CD}_{3} \mathrm{OD}$, (e) $\mathrm{CDCl}_{3} /$ DMSO-d $d_{6}$ 


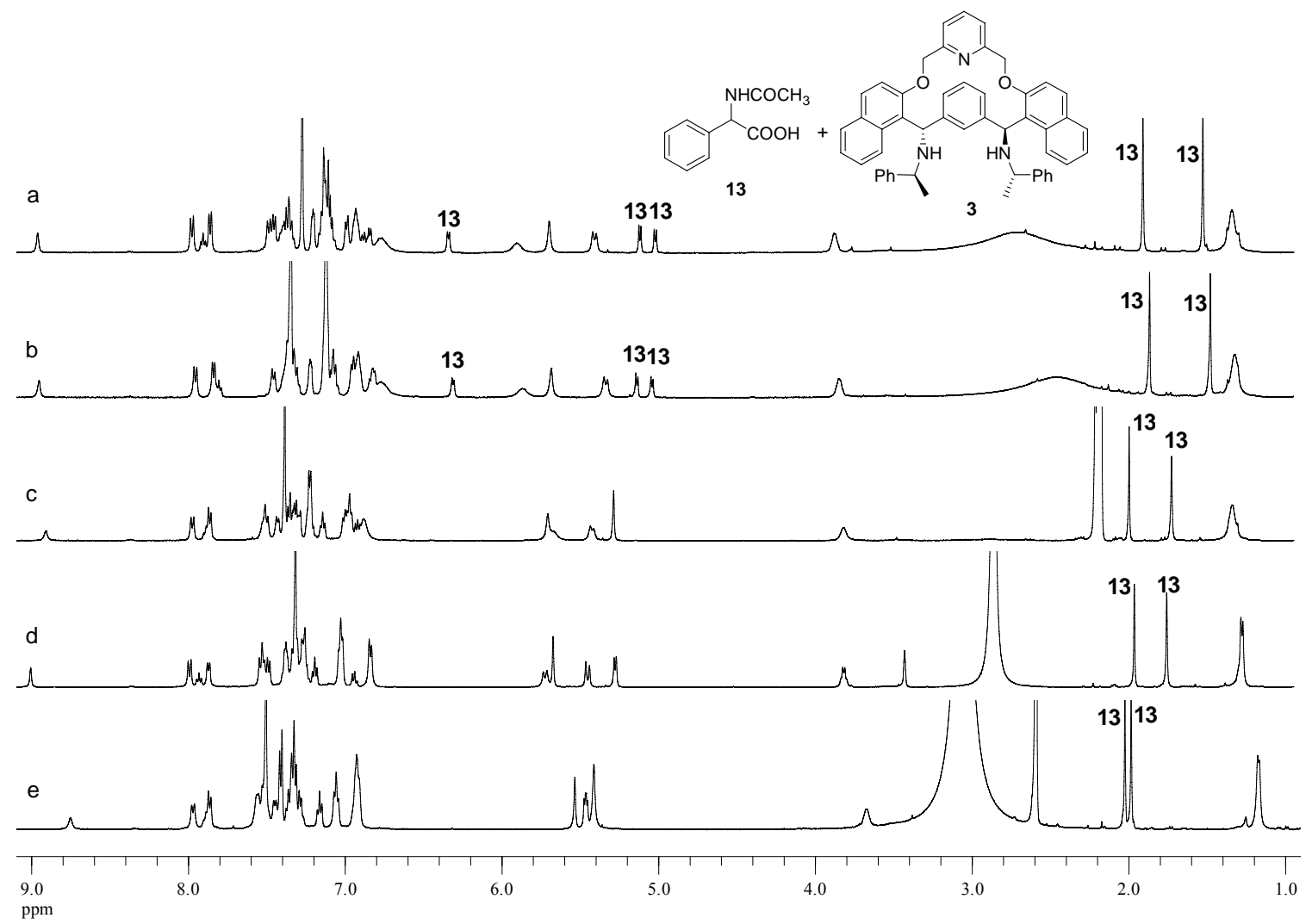

Figure S20. The overlaid ${ }^{1} \mathrm{H}$ NMR spectra $(500 \mathrm{MHz})$ of the 1:2 mixture of host $\mathbf{3}$ and guest $\mathbf{1 3}$ in various deuterated solvents. (a) $\mathrm{CDCl}_{3}$, (b) $\mathrm{CDCl}_{3} /$ benzene- $d_{6}$, (c) $\mathrm{CDCl}_{3} /$ acetone- $d_{6}$, (d) $\mathrm{CDCl}_{3} /$ $\mathrm{CD}_{3} \mathrm{OD}$, (e) $\mathrm{CDCl}_{3} / \mathrm{DMSO}-d_{6}$,

\section{Determination of enantiomeric purity of mandelic acid.}

To evaluate the accuracy of our determining method, we prepared six samples containing mandelic acid with $0,10,30,50,70$ and 90\% ee, respectively (all samples were prepared by adding 0.1 equiv (not exactly) of host 3 in the solutions of mandelic acid $\left(5 \mathrm{mM}\right.$ in $\left.\mathrm{CDCl}_{3}\right)$ ), and determined their enantiomeric purities in the presence of host 3 by using ${ }^{1} \mathrm{H}$ NMR method. The results, which were calculated based on the integrations of the NMR signals, are shown in Figure S21, and the linear correlation between the theoretical $(y)$ and observed \%ee values $(x)$ are shown in Figure S22. 


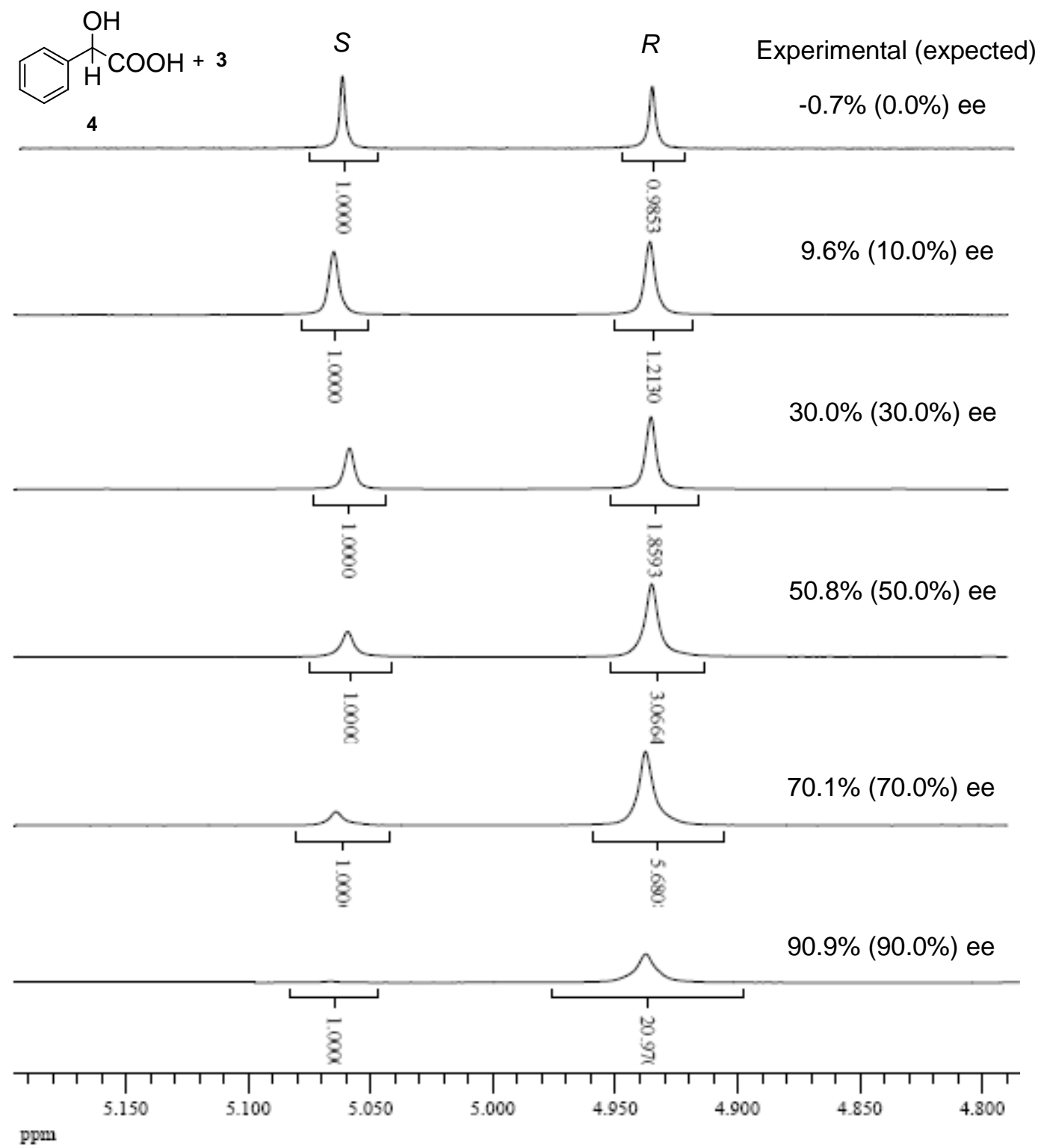

Figure S21. Determination of enantiomeric purity of mandelic acid (ee $\%=R \%-S \%$ ), the $R$ and $S$ in the spectra stand for the $\alpha$-proton of the corresponding isomer of mandelic acids 


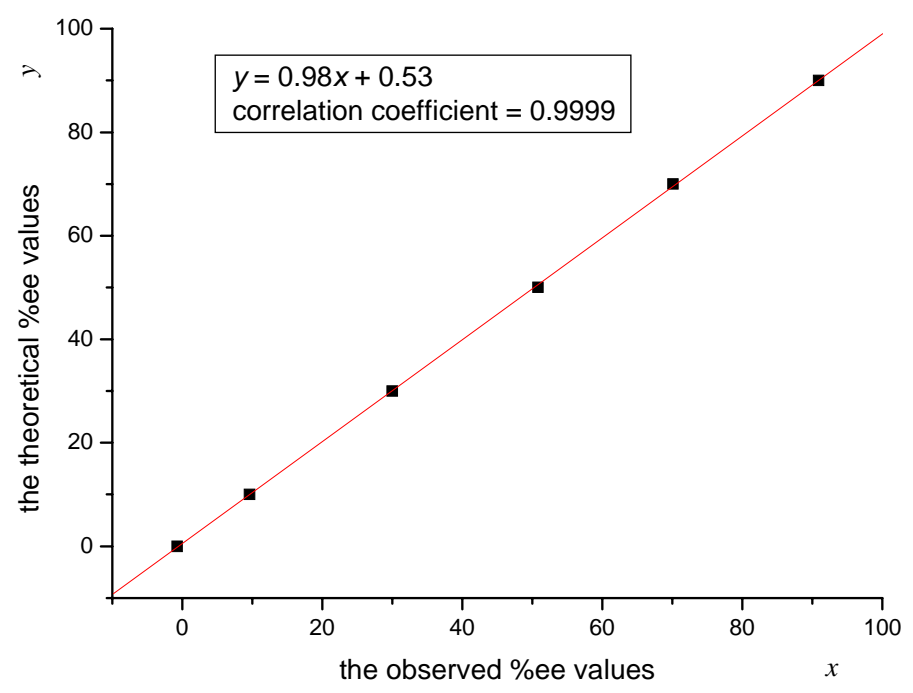

Figure S22. The linear correlation between the theoretical $(y)$ and observed \%ee values $(x)$

\section{References}

(1) (a) Sun, Y.; Li, Z. -M.; Shen, X. -M.; Ma, F. -N.; Zhang, C. Chin. Chem. Lett. 2005, 16, 879-882. (b) Li, Z. -M.; Sun, Y.; Shen, X. -M.; Ai, L.; Zhang, C. Chin. J. Org. Chem. 2006, 26, 465-469.

(2) (a) Blanda, M. T.; Hormer, J. H.; Newcomb, M. J. Org. Chem. 1989, 54, 4626-4636. (b) Connors, K. A. Binding Constants, The Measurement of Molecular Complex Stability; Wiley-Interscience: Newyork, 1987; pp 24-28. 